\title{
An innovative system for piston engine combustion with laser-induced ignition of the hydrocarbon fuel consisting carbon nanotubes
}

The article proposes the concept of a new piston engine combustion system that is designed to meet future-oriented ecological requirements. The concept is to use ethanol as a fuel, in which a slurry of carbon nanotubes would be formed, which are characterized by the ability to ignite using a pulse of laser light fed into the combustion chamber. Modifying the shape of the light beam that penetrates the combustion chamber would allow to control the position and the size of the area in which the ignition of fuel would occur.

The originality of the concept is to combine the latest achievements in the field of nanotechnology in the construction of lasers and the production of biofuels, so as to contribute to improving the environmental performance of engines using the existing synergies.

The article discusses the prospects for the use of bioethanol as a fuel with zero carbon balance, a critical review of related research on light pulse initiated ignition of hydrocarbon fuels from carbon nanotubes was presented, and a review of studies of laser ignition for conventional fuels. The results of studies of carbon nanotubes suspensions in a variety of fuels conducted by the authors in order to seek solutions for the stable dispersions formation, that are resistant to nanotube agglomeration and sedimentation. The summary indicates directions for further research highlighting the importance of environmental impact.

Key words: ethanol, carbon nanotubes, laser induced ignition

\section{Timeline of the development of internal combustion engines in automotive applications}

Reciprocating internal combustion engines have been used in car drives for over a hundred years, but in recent years there has been a growing tendency to replace them with electric motors. These types of efforts are politically motivated or dictated by fashion - ecology and modernity, but are devoid of rational technical justification. It is also worth noting that neither the electric nor hybrid vehicles can be regarded as an invention of modern times.

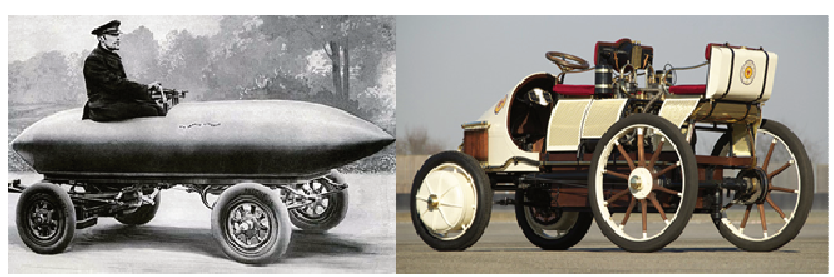

Fig. 1. Nineteenth century electric car, which for the first time exceeded the speed barrier of $100 \mathrm{~km} / \mathrm{h}$, and an early twentieth century hybrid diesel-electric vehicle

Road transport is one of the main sources of carbon dioxide and toxic air pollutants emissions. Air pollution continues to be a problem, especially in large cities, demanding an urgent solution. In this case the elimination of vehicles with combustion engines from city centers and replacing them with electric drive buses and taxis is an effective solution that can be quickly implemented. Such actions make sense, if they are local in nature, but striving for global replacement of combustion engines with electric motors as quickly as possible makes no sense. Well-to-wheel analysis indicates that as long as electricity is produced mainly in power plants burning fossil fuels the replacement of automotive internal combustion engines with electric motors will not bring a radical improvement in transport ecology. Currently about $67 \%$ of globally generated electricity is produced in power plants through the burning of fossil fuels. The development of renewable energy sources does not even compensate for the power lost due to nuclear power plants shut offs, as a result the share of energy derived from fossil fuels does not even decrease [47].

In the case of electric cars the unfavorable ratio of stored energy to the battery mass remains an unsolved problem. If coordinated action is planned and initiated the challenging technical task of dramatically increasing the battery electricity concentration could be realized in the future; as in the past a clearly defined plan allowed building a vehicle in a few years that allows man to fly to the moon.

An alternative to the search for solutions to increase the electricity concentration on board the electric vehicles is to improve the existing internal combustion engines. The authors believe that when determining further directions of automotive industry development the first consideration to take into account is the ratio of the expected benefits to the cost of a project and not its ambition. In this context, it is reasonable to strive for improvements to internal combustion engines; where the ecological and economic aspects play a special role. The environmental performance cannot, however, be seen as a formal meeting of the current tests requirements, but to ensure that the actual emission of toxic compounds is as small as possible in all operating conditions [38-40]. LCA analysis is an important issue. The paradigms presented above are the basis of the new piston engines combustion system concept proposed in the article.

\section{Innovative ethanol combustion system}

The presented concept involves the use of ethanol as a fuel, wherein a suspension would be formed from carbon nanotubes. Carbon nanotubes ignite under the influence of 
a strong beam of light. Ignition of ethanol atomized and vaporized in the cylinder would follow from carbon nanotubes, ignited with laser light. The use of a laser would allow greater freedom in shaping the light beam, and therefore the fuel ignition would occur locally - in one or several locations in the cylinder, simultaneously or in a predetermined sequence. It would also be possible to initiate bulk ignition by splitting the laser beam, ensuring a sufficient concentration of energy. Likewise, operating a laser ignition system could be applied to other fuels, including gasoline or gaseous fuels. Choosing ethanol is dictated by its physical and chemical properties, and environmental characteristics that predispose it as fuel for future engines, as well as the ease of creation and stability of cnt suspensions in ethanol.

\section{Ethanol as fuel for future engines}

Ethanol is widely used as a petrol additive both in Europe and in the USA, while its share in the fuel does not normally exceed $5-10 \%$. It is assumed that the maximum safe ethanol content in gasoline for the conventional automotive SI engines is around 10-15\%. The Worldwide Fuel Charter recommends not to exceed $10 \%$ in its latest edition of 2013 [64]. Such fuel can be burned in standard spark ignition engines and the benefits from the addition of ethanol rely primarily on increasing the fuel resistance to knock, reducing greenhouse gas emissions and making the economy less reliant on oil. These benefits are obviously limited by the small share of ethanol in the fuel, but due to the total amount of fuel consumed it still has some economic importance. The world's largest ethanol producer is the US, where ethanol is produced mainly from corn, and the increase in production over the last decades was mainly due to its use as an additive to gasoline (Fig. 2).

Increasing the share of ethanol in fuel for SI engines or even using pure ethanol instead of gasoline is possible, but requires engine and fuel supply system adaptation. Changes in the fuel system boil down to increasing the material corrosion resistance and using seals resistant to ethanol. In the engine itself the changes needed to allow ethanol combustion involve the use of modified fuel mixture composition control software, in order to take into account the specific nature of the chemical reaction of ethanol combustion. These changes are sufficient, if ethanol is treated as a substitute for gasoline, especially in naturally aspirated engines of the older generation. This solution has been in use in Brazil for many decades, and experience shows that the use of ethanol, even as a standalone fuel without the addition of petrol, does not lead to serious operating problems. The only limit is the approximately 30\% increased volume of ethanol fuel consumption compared to gasoline, and the need for extra starting fuel and/or fuel and air heating systems during start-up and warm-up phase of the engine. Vehicles adjusted for supply with any mixtures of ethanol and gasoline are called FFV (Flexible Fuel Vehicle). In the case of modern engines it also indicates a potential problem of lubricating oil dilution with ethanol and water condensing in the cylinders as a result of the intensive cooling due to ethanol evaporation. Warming the oil up to operating temperature, however, causes rapid evaporation of ethanol and restores the original oil properties [50]. The basic prop- erties of ethanol relevant to engine operation are shown in Table 1 .

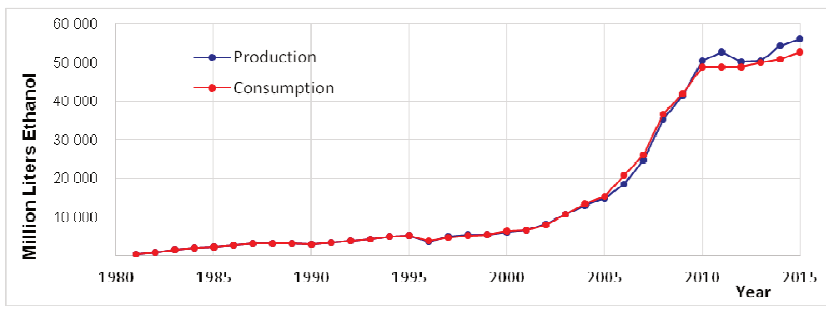

Fig. 2. Production and consumption of ethanol in USA [65]

Table 1. Properties of ethanol as engine fuel

\begin{tabular}{|l|l|c|c|}
\hline \multicolumn{2}{|l|}{ Parameter } & Ethanol & Gasoline 95 \\
\hline Density at $20^{\circ} \mathrm{C}$ & {$\left[\mathrm{kg} / \mathrm{m}^{3}\right]$} & 789 & 750 \\
\hline Research octane number & - & 109 & $>95$ \\
\hline Motor octane number & - & 90 & $>85$ \\
\hline Heat of evaporation & {$[\mathrm{kJ} / \mathrm{kg}]$} & 841 & 330 \\
\hline Heating value & {$[\mathrm{MJ} / \mathrm{kg}]$} & 26.8 & 43.5 \\
& {$\left[\mathrm{MJ} / \mathrm{dm}^{3}\right]$} & 21.2 & 31.8 \\
\hline $\begin{array}{l}\text { Stoichiometric air-fuel } \\
\text { mixture }\end{array}$ & {$\left[\mathrm{kg}_{\text {air }} / \mathrm{kg}_{\text {fuel }}\right]$} & 9.0 & 14.3 \\
\hline Distillation & {$\left[{ }^{\circ} \mathrm{C}\right]$} & 78 & $40-215$ \\
\hline Flash-point & {$\left[{ }^{\circ} \mathrm{C}\right]$} & 13 & -43 \\
\hline $\begin{array}{l}\text { Kinematic viscosity } \\
\text { at 40 }\end{array}$ & {$\left[\mathrm{mm}^{2} / \mathrm{s}\right]$} & 1.2 & 0.5 \\
\hline $\begin{array}{l}\text { Elementary composition } \\
\text { C }\end{array}$ & {$[\% \mathrm{~m} / \mathrm{m}]$} & & 84.8 \\
$\mathrm{H}$ & & 52.2 & 13.3 \\
O & & 13.0 & 2.4 \\
\hline
\end{tabular}

While ethanol was formerly treated as a substitute for gasoline - in Brazil, or as an organic additive - in Europe and the US, it is now turning out that ethanol can be a very attractive fuel for future engines [50]. With the continued trend of downsizing and further increase in boost pressure, and thus inevitably - pressure and temperature in the cylinder, ethanol may end up being a more suitable fuel than gasoline.

Engine downsizing is an effective method of reducing fuel consumption, and therefore the exhaust emissions of greenhouse gasses, and the obtained benefits are directly related to the degree of downsizing. The mechanical and thermal loads of engine components are the barrier to further increasing engine unit power, and in the case of SI engines also the problem of knocking, especially the socalled extreme knocking $[62,63,70]$. In the case of very large boost pressure even a single phenomenon of spontaneous mixture ignition initiated from hot components in the engine head (known as hot spots) can cause permanent damage to the piston-cylinder components [62]. As a result engines of this type use a two thermostats cooling system which ensures a lower temperature of the fluid flowing through the cylinder head in comparison to the rest of the engine block, sub-optimal compression ratios are used due to the engine efficiency, the air fuel mixture is deliberately enriched under maximum load conditions to cool the combustion chamber and the ignition is delayed [60]. All these activities lead to a significant deterioration in engine performance. As an extreme example of this is the ignition timing curve in the SI engine with direct fuel injection and 
turbocharging range, as registered during the maximum acceleration road test at top gear and engine speed of 1,500 rpm. To prevent excessive pressure buildup and knock burning, the ignition in these conditions is delayed up to several degrees after TDC (Fig. 3).

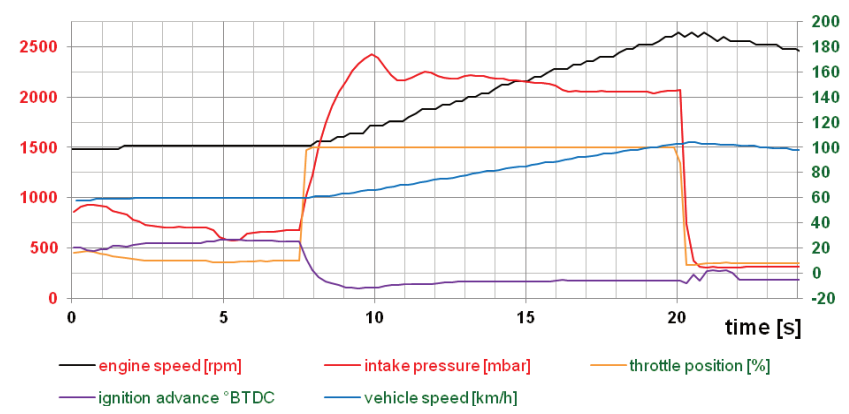

Fig. 3. The characteristic of selected parameters of a TSI type BLG engine during a maximum acceleration road test of a VW Golf, the parameters listed in the legend are color coded with the axis labels [30]

Regarding the relations described above, the characteristics of ethanol are extremely valuable, such as high octane number and a large vaporization heat, which contribute to the effective cooling of the cylinder fuel mixture [50]. An engine designed for ethanol fuel may have a higher compression ratio, thus significantly improving the overall efficiency under low and medium load, a similar effect relates to the accelerated ignition. On the other hand, under high load enriching the fuel mixture to cool the cylinder can be skipped, which in modern petrol-fueled engines of this construction like the TSI engine shown, significantly deteriorates their performance. It should be pointed out that resistance to ethanol knock depends on the engine operating conditions to a greater extent than it does for petrol. A parameter called the fuel sensitivity, representing the difference between the octane numbers RON and MON is about 10 for gasoline, and about 20 for ethanol.

The use of ethanol as fuel for internal combustion engines will not only reduce greenhouse gas emissions but is also beneficial in terms of nitrogen oxides emissions and hydrocarbons [53]. These benefits outweigh the negative consequences of increased emissions of acetaldehyde [23, 54]. One drawback of vehicles fueled with ethanol is the increased emissions by evaporation from the fuel supply system [19].

Developing industrial ethanol production on a mass scale is also justified by the fact that in the long term, it can become an energy carrier for fuel cells. For this application ethanol can be much more attractive than hydrogen, for which the chain of production, distribution, transportation and conversion into electrical energy is characterized by low efficiency and high environmental cost.

While today ethanol produced on an industrial scale comes from raw materials that could become food - corn in the US, sugar cane in Brazil or grain in Europe, it is possible to develop its production from wood waste or organic waste in the future.

European ethanol is usually produced from cereals and potatoes. In the US, Canada and China, the main raw material is corn. The largest amount of the world production of ethanol (approximately 60\%), however, comes from the processing of sugar cane. This raw material is used, among others, in Brazil. The raw materials for bioethanol production can generally be divided into three groups [6]:

- containing sucrose: sugar cane, beetroot, sorghum, and some fruit,

- containing starch: wheat, rye, barley, potatoes, corn, rice, cassava,

- lignocellulosic biomass: energy crops, by-products from agriculture and the timber industry, paper and cardboard as fraction of municipal waste.

Bioethanol produced from last group raw materials belongs to 2nd generation of biofuels. While today ethanol on a commercial scale is produced mostly from materials which can be used for food purposes, the expansion of ethanol production from wood waste or discarded food remains is expected to grow significantly.

\section{Carbon nanotubes}

\subsection{Basic information regarding cnt}

Carbon nanotubes are one of the allotropic forms of carbon, such as: graphite, diamond, fullerene, graphene and a variety of amorphous variations. These allotropic varieties differ radically in their physical and chemical properties. Such differences arise from the spatial structure of crystalline carbon atoms and their interactions. The structure schematic of selected varieties of allotropic carbon are shown in Figure 4.
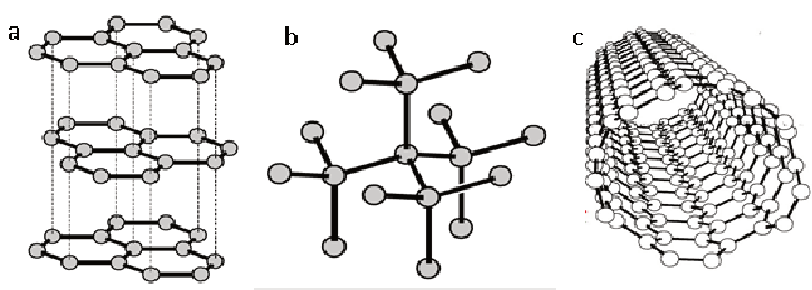

Fig. 4. Crystalline structure of graphite (a), diamond (b) and carbon nanotube (c)

The carbon nanotube shown in Figure 4 is a singlewalled carbon nanotube (SWCNT), characterized by the simplest structure; a more common variant are, however, multi-wall carbon nanotubes (MWCNT) formed from concentrically superimposed single-wall nanotubes with different diameters. By purposefully adjusting the growth precursor selection of nanopowder metal as well as the atmosphere and temperature of the CVD (Chemical Vapor Deposition) process, it is possible to obtain both of these nanotube variants with lengths ranging from a few nanometers to many micrometers and a controlled diameter. The diameter of single-wall nanotubes is typically between 1 to $2 \mathrm{~nm}$, multi-wall nanotubes have diameters from 2 to more than tens of $\mathrm{nm}$, wherein the separation between successive concentric layers is fixed at $0.36 \mathrm{~nm}$ [9].

Graphite, diamond, and amorphous carbon form sometimes imprecisely referred to as DLC (diamond like carbon) - all found industrial applications, including in the construction of internal combustion engines [59]. Carbon nanotubes were discovered in the '90s of the last century, but particularly intense development of nanotubes research 
occurred at the beginning of the XXI century. A number of laboratories was established, which could grow, study, and develop nanotubes applications, but only a few of them have survived to this day [67]. Carbon nanotubes still primarily remain the subject of intensive applications research, and their industrial applications are relatively few in number as of yet $[8,10,20]$. The increase in carbon nanotubes production makes their price is halved every year $[9,67]$, and ceases to be a barrier preventing many of the possible industrial applications.

Because of their many functionally significant characteristics, from the engineering perspective, carbon nanotubes significantly exceed the best previously known conventional materials. It seems that their practical applications are limited so far because any engineering design can find a material characterized by a set of functionally essential characteristics. In this group of functionally significant characteristics the most crucial is the weakest feature, like the weakest link determines the strength of the chain.

\subsection{Carbon nanotubes interaction with light}

Among the many unique features that the carbon nanotubes possess is their ability to ignite under the impulse of light, e.g. a normal camera flash, was recognized relatively early. This phenomenon was found for single-wall carbon nanotubes grown in the CVD process, and untreated (pristine CNT) forming a small low density sample, giving it a "fluffy" appearance. The power density required to ignite a sample of SWNTs having a density of $0.2 \mathrm{~g} / \mathrm{cm}^{3}$ is about $100 \mathrm{~mW} / \mathrm{cm}^{2}$. In an attempt to understand the basic physical phenomena the role of light absorption with a broad wavelength spectrum was emphasized, extremely high heat conductivity typical of nanotubes, and the oxidation process. It was estimated that the local temperature of nanotubes must exceed $1500^{\circ} \mathrm{C}[1]$.

A purely thermal mechanism may be insufficient to describe the self-ignition of carbon nanotubes, especially when using a monochromatic light source such as a laser [3, 57]. In [58] attention was drawn to the fact that the nanotubes ignition under the influence of a light pulse is accompanied by a photo-acoustic effect, the resulting sound pressure level is sufficient to modify the structure of the nanotubes. Most importantly, however, it has been shown that the presence of iron nanoparticles, which are used as a catalyst for initiating growth of the nanotubes in the CVD process, is essential for the light-induced ignition of the nanotubes. These particles are usually not removed, and they are the main contaminant of nanotubes described as pristine cnt or industrial grade cnt, after the removal of these contaminants the nanotubes lose the self-ignition ability. In order to explain the process of light-induced spontaneous combustion it can be assumed that the iron nanoparticles oxidize generating heat which initiates a chain reaction [58]. Showing the key role that nanoparticles of iron play in this process also demonstrated that both single-walled and multi-walled nanotubes can ignite when exposed to light. In [56] a quantitative analysis of chemical reactions proposed in [58] was conducted, validating the assumed course of spontaneous combustion mechanisms.

An interesting case is described in [52] where spontaneous ignition of a polyurethane-nanotube composite was observed during Raman spectroscopy. The ignition was caused using a laser beam having a wavelength equal to $632.8 \mathrm{~nm}$, and low output power typical for measurements with the Raman method. It was further noted that neither the nanotubes nor the polyurethane present in the composite underwent spontaneous ignition when illuminated with laser light on their own, not until they were combined into a composite with very high nanotube dispersion. The key factor towards explaining the ignition of the composite is that the carbon nanotubes used in it have the maximum light absorption wavelength of approximately $650 \mathrm{~nm}$, similar to the laser wavelength. The polyurethane is transparent for this wavelength, but by surrounding the nanotubes it insulated them thermally from the environment, whereas the porosity of the composite allowed for oxygenaccess and for the combustion to initiate [52].

By pulverizing the composite with the carbon nanotubes and the oxidizer sealed in the transparent resin a fuel additive can be made, which under the influence of light initiates combustion. Similar solutions were tested successfully in [5]. IDEM also indicated a quantitative relationship between the iron concentration in the nanotubes sample and the minimum light-initiated ignition energy. It has been shown experimentally that the phenomenon of lightinitiated ignition of carbon nanotubes can be used for igniting liquid fuel. A particularly wide range of carbon nanotubes suspension concentrations, which can provide a light initiated ignition, was observed for methanol [5].

Carbon nanotubes are not the only nanomaterial for which the ignition can caused by a flash of light, a similar phenomenon was described for aluminum nanopowder [45].

In addition to the research relating to light-induced ignition of nanoparticles outlined above, a number of studies was performed aimed at the use of carbon nanotubes as an additive for engine fuel allowing light initiated ignition. The conclusions listed below can be formulated on this basis. Consideration should be given, however, that the dominant part of the studies conducted so far used xenon lamps as a light source; differing from the nanosecond $\mathrm{Nd}^{3+}$ :YAG laser in that they emit non-coherent out of phase light in a broad wavelength spectrum, with burst duration of at least a thousand times longer and a low energy density.

- Light induced ignition requires the lowest amount of energy when using single-wall carbon nanotubes with carbon content of over $40 \%$ [4].

- Using a xenon lamp in combination with different broadband filters, there was no strong correlation between the minimum ignition energy of the nanotubes and the wavelength of the incident light, thus photothermal nature of the ignition phenomenon was adopted [4].

- A strong relation between the pulse duration and the minimum energy required to initiate ignition was found, the shorter the pulse the less energy was needed [4].

- The use of carbon nanotubes and light induced ignition accelerates the process of gas burning (methane, ethane) and expands the flammability limits in comparison with spark ignition [23]. 
- The use of laser changes the nature of the mixture combustion process from deflagration to detonation [57].

\subsection{Nanotubes in the piston engine combustion process}

Carbon nanotubes are formed naturally in a piston combustion engine and their presence in the exhaust has been proven in studies presented in [21, 35-37]. The nanotubes present in the exhaust gas have a relatively short length, due to their short period of growth limited by the length of the combustion cycle [36]. The process of formation of nanotubes occurs intensively in spark ignition engine, powered by petrol or gas. In [2] it was demonstrated that growth of nanotubes can be purposefully continued outside the cylinder engine - on a metal plate placed in the exhaust system. Carbon nanotubes, same as soot, have the ability to adsorb the particles of toxic pollutants present in the exhaust gas to their surface as well as agglomeration.

It seems that especially important results were shown in [55], where it is indicated that the ferrocene $\left[\mathrm{Fe}\left(\mathrm{C}_{5} \mathrm{H}_{5}\right)_{2}\right]$ present in small amounts in the fuel causes a drastic increase in the emission of carbon nanotubes, where nanotubes present in the exhaust gases contain nanoparticles of iron with diameters of 5 to $10 \mathrm{~nm}$. This process occurs intensively in diesel fuel with high sulfur content. The results are disturbing, because ferrocene is a widely used catalytic additive to diesel fuel; it is also used to increase the octane number of gasoline. The results obtained in [55] are completely understandable when considering the similarity of conditions in the cylinder of the running engine and the reactor deliberately growing nanotubes (cnt growth) in the CVD process, and iron nanoparticles are normally entered in this process as precursors for nanotubes growth.

The results shown in [55] indicate the need to exercise extreme caution in proposing such combustion systems concepts which require the addition of metallic nanoparticles into the fuel. The results of many of the conducted experiments lead to expect that nanotubes added to the fuel (fuel-borne) will have been burnt in the cylinder, causing relatively harmless carbon dioxide and carbon monoxide, whereas metallic additives can potentially become a source of secondary emissions, especially of carcinogenic nanotubes decorated with metallic nanoparticles. The indicated problem undoubtedly requires further studies. On the one hand, the action mechanism of carcinogenic carbon nanotubes and accompanying conditions have not yet been clearly understood, on the other hand, the results of recent work clearly indicate the beneficial effect of fuel metallic nano-additives in the combustion process.

In [51] the existence of a synergistic effect resulting from the simultaneous addition of carbon nanotubes and cerium oxide to fuel diesel engine was indicated. Significant benefits were obtained despite using low concentrations of both types of nanoparticles in fuel of up to 100 ppm. The carbon nanotubes act as a catalyst to accelerate the burning rate which results in decreased ignition delay and causes the lower heat release rate and advancement of the peak heat release rate. The cerium oxide nanoparticles act as an oxygen donating catalyst, which provides oxygen for the oxidation of carbon monoxide and absorbs oxygen for the reduction of nitrogen oxides [51]. The synergistic effect of the addition of functionalized carbon nanotubes and cerium oxide to biofuel for a diesel engine is also described in [41], more broadly, the issue of nano-additives to biofuels was discussed in [7, 48, 49].

Carbon nanotubes were also added to fuels for SI engines, which proved to be an effective anti-knock addition as well as raising the octane number [34].

In a number of works increases of the hot-plate ignition probabilities of ethanol due to the introduction of several different types of NP suspensions were found. Nanoparticles such as $\mathrm{Al}_{2} \mathrm{O}_{3}, \mathrm{Fe}_{3} \mathrm{O}_{4}$, and carbon nanotubes were tested $[25,26,29]$. In the engine operation aspect the most promising seems to be the observed rapid evaporation of the suspension of nanotubes in ethanol when compared to pure ethanol, [26, 29].

A relatively large number of publications relates to gas engines research in which the combustion process has been successfully modified through the addition of carbon nanotubes. A particularly valuable feature of nanotubes is in this case the acceleration of the lean mixtures combustion and extending the boundaries of the combustion of lean mixtures, as reported in [11-13].

\subsection{Carbon nanotubes in hydrocarbons suspensions}

Nanotubes are not solubilized, rather they are suspended as individual particles in the fluid, like an ink or paint. Carbon nanotube suspensions can be made in a number of ways, and with a number of fluids, where due to the method of suspending the solvents they can be split into polar and nonpolar. It is useful to start by modeling the nanotubes as rigid rods in a liquid suspension, to determine how far apart they may be for a given concentration.

When particles with a large aspect ratio (like carbon nanotubes) are dispersed in a solvent, they will rotate, due to the Brownian motion or in the presence of a velocity gradient (flow). This rotation creates a large effective hydrodynamic radius, and each nanotube sweeps through a spherical volume. For a nanotube with an aspect ratio of $\mathrm{a}=$ $=\mathrm{L} / \mathrm{d}$, the ratio $(\mathrm{R})$ of the nanotube's actual volume $\mathrm{V}_{\text {actual }}=$ $=\left(0.785 \mathrm{a} \mathrm{d}^{3}\right)$ to the volume of the swept sphere $\mathrm{V}_{\text {sphere }}=$ $=\left(0.523 \mathrm{a}^{3} \mathrm{~d}^{3}\right)$ simplifies to: $\mathrm{R}=3 /\left(2 \mathrm{a}^{2}\right)$. Aspect ratios for carbon nanotubes are equal to $\sim 2000$. For example, MWCNT are often 20 microns long and $10 \mathrm{~nm}$ in diameter, and SWCNT are often 2 microns long and $1 \mathrm{~nm}$ in diameter. The volumetric ratio $\mathrm{R}$ for nanotubes of this aspect ratio is $4 \times 10^{-5}$ vol\%, which is less than 1 milligram per liter. At any greater concentration, the nanotubes will intrude upon each other's hydrodynamic spheres and hinder each other's rotation. This is the primary reason that nanotube suspensions are difficult to make and increase in viscosity quickly.

Nanotubes will interact with each other's hydrodynamic radius at any appreciable concentration. This would result in entanglement and the creation of large agglomerates, if there was no repulsive force to keep them from aggregating. When pristine nanotubes are suspended in hydrocarbons, they will aggregate and form a loose sediment on the bottom of the container, with a clear supernatant. To provide a repulsive force, it is necessary to electrically charge the nanotubes so that they repel each other and prevent agglomeration from occurring. This may not completely stop gravity-induced settling, but any sediment will then be made up of individual nanotubes, not agglomerates [68]. 
Pristine SWCNTs form „bundles” out of parallelarranged, adjacent side walls of the CNTs. Multi-walled carbon nanotubes (MWCNT) are entangled in a chaotic tethered pattern of crossed fibers forming a mesh configuration $[14,28,69]$. The number of contacts which can form between neighboring MWCNTs increases dramatically with the length of the CNTs. Therefore, the binding of a clustered network of long MWCNTs is extremely strong, where each contact effectively acts as a cross-link fixing the network together [28]. The use of short CNTs therefore seems to be a simple and effective way that allows for obtaining a good dispersion. Figure 5 shows a comparison of the samples with ethylene glycol to which pristine MWCNTs were added. The CNTs were obtained using the same CVD process, but some of them have undergone a longer mechanical milling process, so that their length is much shorter. After adding the pristine CNTs the samples were only shaken by hand, they were not sonicated at all.

The dispersion of CNTs in low viscosity liquids, such as gasoline and ethanol can be effectively supported by the sonicating process. Ultrasonicating can effectively break SWCNT aggregates without damaging their structure; in the case of MWCNT effective breakdown of agglomerates is associated with the shortening of length of the CNTs predicted by theoretical considerations [28] as well as confirmed in several independent experiments. Both theoretical considerations [28] and experiments [14] indicate that after a long sonicating time a defined target length of the CNTs is obtained and the process of further shortening does not occur. The authors' own experiments show that the sonicating process is not effective in the case of viscous liquids such as lubricating oil or diesel fuel. In contrary to sonication, using dispersion by shear-mixing can be effective in viscous fluids [32].

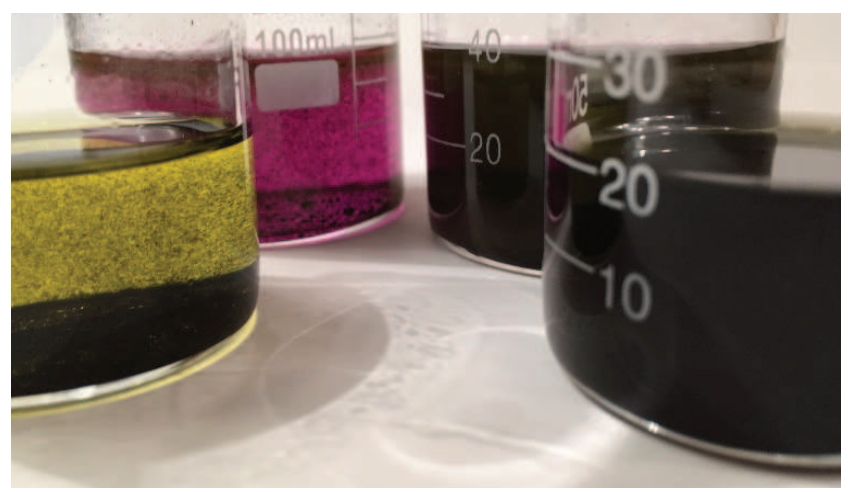

Fig. 5. Comparison of pristine MWCNT, long (5-20 $\mu \mathrm{m}$, two on the left) and short (1-3 $\mu \mathrm{m}$, two on the right) dispersion in ethylene glycol (Volkswagen Brake fluid DOT 4 two at the front and G13 cooling liquid concentrate two at the back)

Visual inspection of the nanotubes dispersion in hydrocarbons has a preliminary character, however, after conducting a series of experiments with different types of carbon nanotubes and various hydrocarbons, it can be concluded that using ethylene glycol allows for extremely easily obtaining relatively stable suspensions. In most cases, however, shortening of carbon nanotubes is not an effective method for obtaining a satisfactory dispersion degree and then the rule is to use different physical and chemical processes, with the aim to induce electric charge in the nanotubes. Electrically charged nanotubes repel each other, which impedes agglomeration, but does not always prevent sedimentation. Even if sedimentation occurs the resulting precipitate consists of individual nanotubes rather than their agglomerates, which makes redispersion dramatically easier.

In practice, it is extremely difficult to anticipate the ability of a certain type of nanotubes to form a suspension in a certain solvent. The multiple experiments by the authors lead to the conclusion, that among commercial fuels, the formation of a stable suspension in diesel fuel has proven the most challenging, similarly in vegetable oils. Obtaining a stable cnt suspension in commercial gasoline is much easier. However, even compared to gasoline ethanol is a very good solvent for the nanotubes. For this reason it is often used in many chemical treatment processes of nanotubes, and sometimes it is virtually impossible to obtain nanotubes sedimentation in ethanol, even after prolonged centrifugation [68]. An example of a bad solvents are Hexanes, seen in Fig. 6 which shows a sample of Hexanes, gasoline and ethanol in which that obtaining the dispersion of the nanotubes with the bamboo type structure was attempted, with diameter of about $30 \mathrm{~nm}$ and a length in the range of 1-5 microns. The nanotubes are electrically charged by the incorporation of $\mathrm{COOH}$ groups on their surface. ODA (Octadecylamine) and HATU were used in the preparation process among others. The illustrational, although representative nature of the results presented in Fig. 6 should be emphasized; the use of specific nanotubes and their preparation procedures can lead to a reversal of suspension quality obtained for gasoline and ethanol.

Visual inspection of the contents of sample no. 14 comprising a cnt suspension in ethanol does not allow to visually determine the presence of any agglomerates. Figure 7 compares pictures of the resulting dried fuel droplet from the sample no. 14 and 12 applied to a sheet of paper as seen by light microscopy.

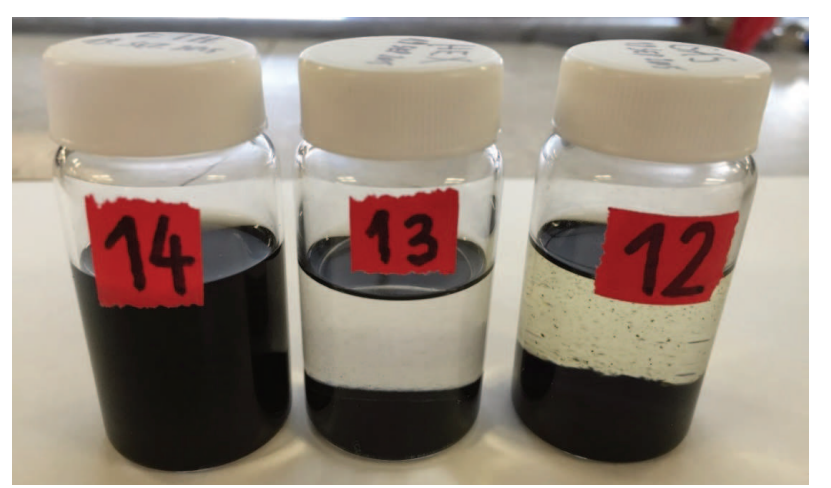

Fig. 6. Attempt at obtaining a similar concentration bamboo-structure MWCNTs solution, in ethanol (vial no. 14), hexanes (vial no. 13) and US commercial gasoline (vial no. 12)

An image obtained using a simple optical microscope allows for a clear illustration of the difference in size of the cnt agglomerates produced in the gasoline and the practically almost invisible agglomerates in ethanol. Further examination of specimen no.12 is pointless, agglomerates of nanotubes are so large that they would certainly cause improper operation of the fuel supply system of a modern 
engine. It was found that for gasoline significantly better results can be obtained if the multi-walled nanotubes are replaced with single wall carbon nanotubes with a diameter of about $1.5 \mathrm{~nm}$ and a length in the range of $1-5$ microns.

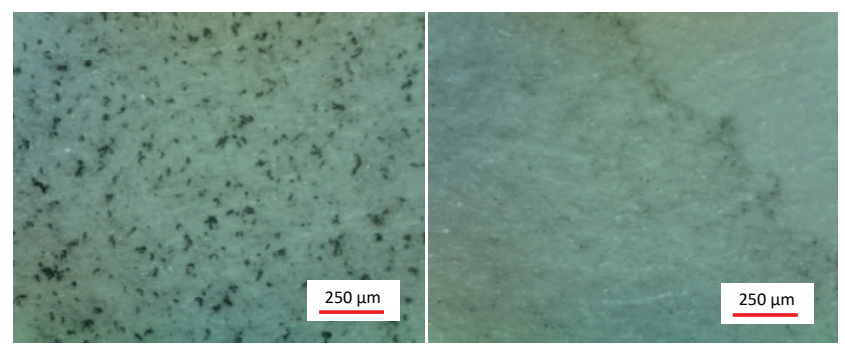

Fig. 7. Pictures of dried fuel drop on a piece of paper, the image from an optical microscope, at $60 \times$ magnification. On the left the fuel sample no. 12 (petrol), on the right no.14 (ethanol)

In order to prepare the sample for SEM to investigate the CNTs dispersion in hydrocarbons a drop of the solution was applied on an aluminum foil and evaporated at room temperature. The process of evaporation was associated with a temporary critical increase in the concentration of CNTs and as a result could have led to the agglomeration of CNTs on the surface of the aluminum foil, thus falsifying the results. It could certainly not, however, give a falsely negative test result for the presence of agglomerates [32].

Figure 8 shows an example of images obtained for ethanol with MWCNTs (as in vial no. 14), the results for the gasoline SWCNT are shown in Figure 9; all the images shown were made using a Field Emission Scaning Electron Microscope JEOL JSM-7001F.

The obtained images allow for the formulation of the comments listed below with respect to the suspension of nanotubes in ethanol.

- When using standard electron microscope it's impossible to measure the cnt agglomerates diameter in liquid fuel (not after evaporation), due to its high partial pressure.

- There is no easy way to measure the cnt agglomerates diameter in real fuel spray, but there are some laser light based method known in engine research, they could be adopted for this task. The laser wavelength set the resolution limit.

- The long time stability over weeks and months couldn't be tested during the short trial.

- The view focused on one of the biggest agglomerates (ca 30 micrometers diameter) shows large surface around covered with well dispersed CNT's. There are some smaller agglomerates or impurities visible in area around.

- The small CNT bundles of about 1 micrometer or less in diameter will be probably not filtered out in the engine fuel supply system. The bigger agglomerates can be probably easy removed by using the centrifuge or dissolved during longer sonicating process; eventually by using other, e.g. mechanical treatment methods.

- In the aspect of laser induced fuel ignition it is unknown if it's desired to keep the cnt's fully dispersed, or maybe the relatively small cnt bundles (1 micrometer or less) can improve the fuel ignition process. The agglomerates of diameter less than 1 micrometer will be probably not critical for the engine injection system, where the nozzle hole diameter is 100 micrometers or more.
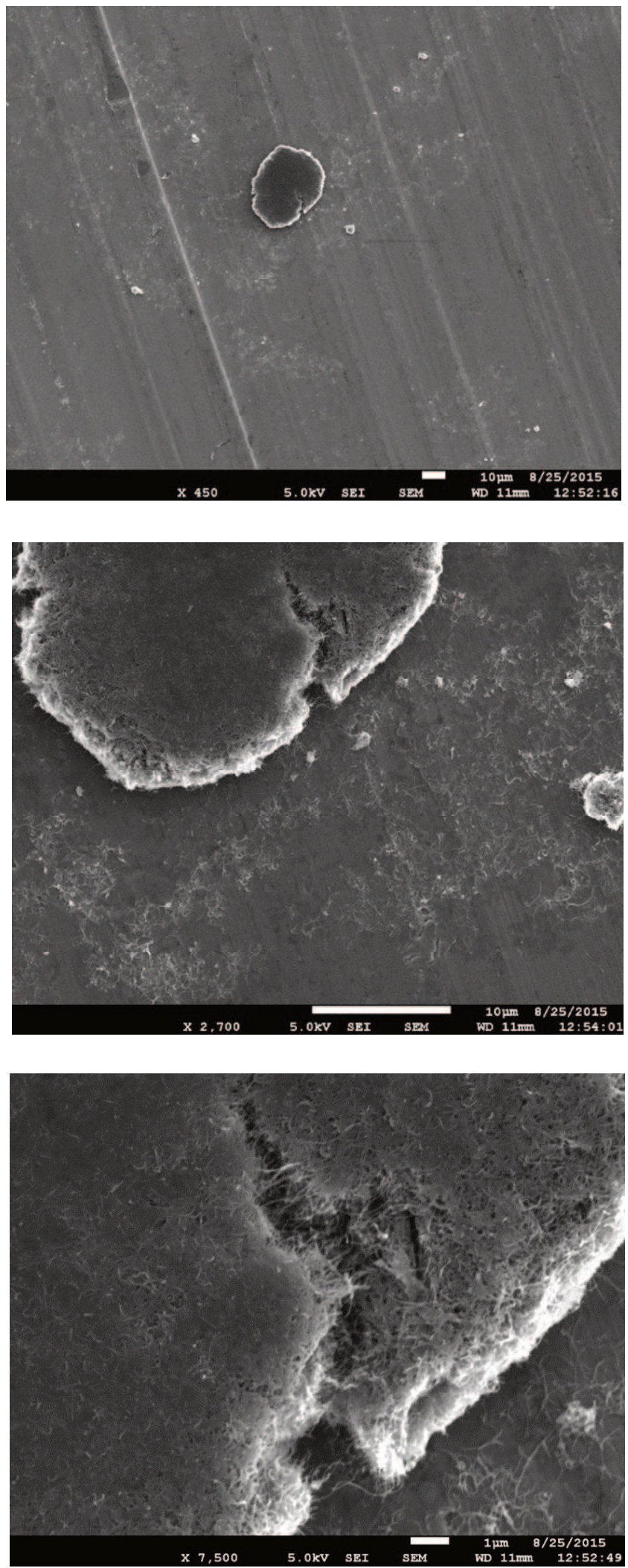

Fig. 8. MWCNT in ethanol (vial no. 14) subsequent images show increasing magnification 


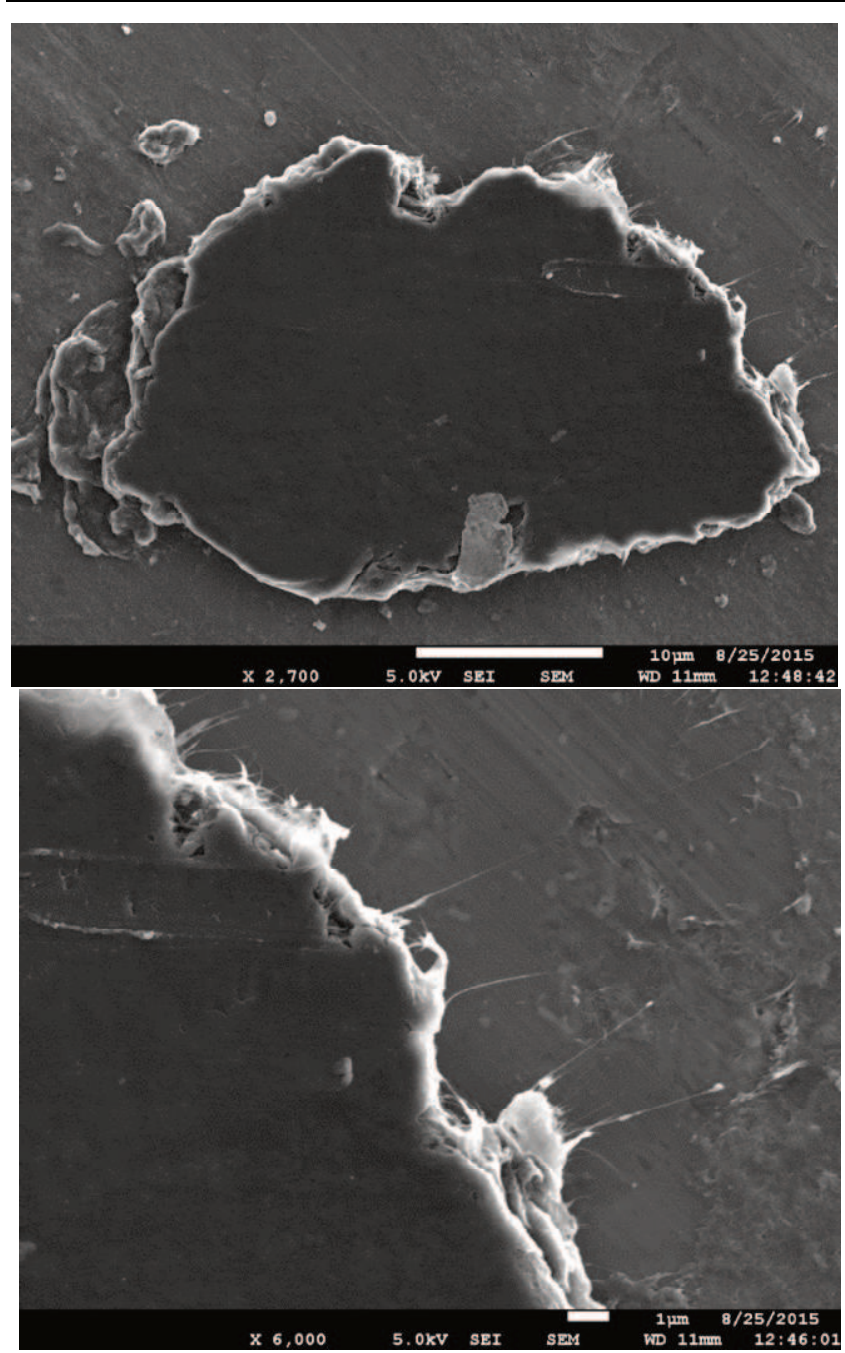

Fig. 9. SWCNT in commercial US gasoline subsequent images show increasing magnification

\section{Laser induced ignition in IC engines}

\subsection{Experiences with the use of lasers in engine proces- ses research}

Lasers of various designs have been used for many years in research of in-cylinder processes, plentiful experience gained in these studies [71, 72] can be used in the ignition concept presented in this article. One of the simplest applications of laser in engine research is its use as a source of light to take a photograph of the fuel atomization process. The authors discussed their experiences in this field in [31]. It is worth noting that a great progress in laser technology has been made in the last decade, especially for $\mathrm{Nd}^{3+}$ :YAG lasers. An example of such a laser for laboratory research is shown in Figure 10 [31, 66]. Such a laser emits radiation at the wavelength of $1064 \mathrm{~nm}$, the second harmonic generator can convert this wavelength into $532 \mathrm{~nm}$. The laser light is generated in the course of pulses lasting several nanosecond. The pulse energy in the wavelength range $532 \mathrm{~nm}$ is equal to $300 \mathrm{~mJ}$. The experience of the authors indicate that in order to achieve correctly exposed images of a fuel jet the impulse energy restricted to a few $\mathrm{mJ}$ is sufficient. Figure 11 shows a comparison of fuel jet photos lit with halogen bulbs and laser light. Pictures were made while maintaining the same parameters of the camera for quick photos. In the first case two lamps with 250 watt bulbs were used and in the second case the image illumination was realized with Laser Continuum Surelite SL II-10 [66].

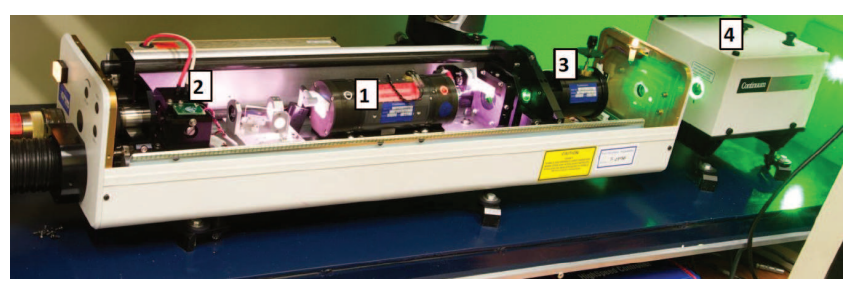

Fig. 10. Impulse $\mathrm{Nd}^{3+}$ :YAG laser with a second harmonic generator prepared for fuel atomization tests. 1: laser head with the rod and pumping lamp, 2: Q-switch, 3: second harmonic generator, 4: harmonic separator [66]

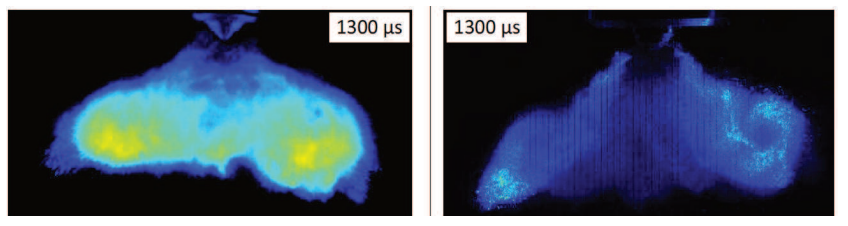

Fig. 11. Comparison between halogen lamps (left picture) and the laser (right picture) as a light source for illuminating the fuel spray injected into the pressure chamber, the two image frames were recorded after 1300 microseconds after the start of the injection [31]

In the authors' opinion, the laser light is more appropriate than a xenon discharge lamp light for the application concept of the ignition of hydrocarbon fuel with a suspension of carbon nanotubes discussed in this article. A number of the unique characteristics of laser light can be used with this solution, as listed below.

- Laser light is monochromatic, and the wavelength is important for its interaction with carbon nanotubes, as demonstrated by the results of Raman spectroscopy, and absorbance measurements $[15,16]$. It is appropriate to use $\mathrm{Nd}^{3+}$ :YAG lasers in engine applications, because of their widespread use and the ability to generate harmonics with a wavelength of $532 \mathrm{~nm}, 355 \mathrm{~nm}$ and $266 \mathrm{~nm}$. The use of light in the ultraviolet range may be advantageous due to their more intensive interaction with carbon nanotubes, however, the energy of these wavelengths is limited due to the enhanced harmonics generator circuit. In addition, delivering ultraviolet light to the cylinder may require the use of special glass screen, such as sapphire.

- Very small divergence of the laser beam allows for the beam to be focused by an optical system on any point in the combustion chamber. The beam can be formed in a targeted manner, for example to form a thin plane (light sheet) which can be used to force ignition not at a point, but in a controlled volume of the cylinder.

- The duration of the laser pulse is limited to a few nanoseconds and a high concentration of energy facilitates the ignition of nanotubes. The flash of a xenon lamp usually lasts longer than 100 microseconds, it is at least 10,000 times longer than a laser light pulse, so even a small laser provides an energy concentration that is virtually unattainable for any other light source. The tests in [17] indicates that a shorter pulse results in a significant reduction of the minimum energy required to ignite the nanotubes. 
- The results of optical studies of in-cylinder processes indicate that contaminants originating from combustion and settling on the cylinder optical access window is one of the key problems. A laser beam directed through a glass window to the interior of the cylinder is effective in burning off impurities and ensure the transparency of the windows [27].

\subsection{Experiences with laser ignition of conventional hydrocarbon fuels}

The laser ignition as an alternative to the conventional ignition system, implemented with an electric spark between the electrodes of the spark plug, has been studied in conventional IC engines for many decades. The original motivation for using the laser system have been attempts to increase the efficiency of fuel burning in conventional engines and reducing emissions. Another factor accelerating the work on the use of laser ignition was a tendency for building lean-burning engines. In particular for engines burning gaseous fuels and the attempt to increase the exhaust gas recirculation level. There are numerous review articles, which examined in detail the results of many studies conducted on the use of laser ignition in engines burning a variety of hydrocarbon fuels [22, 42, 46], thus such a review of results will not be repeated in this article. It has been shown that the replacement of the conventional ignition system with a laser ignition system achieves considerable benefits in improved engine performance and operation. Appropriate technology has been successfully tested in laboratory conditions, but had never been used in mass production. It is worth noting that in terms of the application a breakthrough can be brought about by the development of laser technology observed in recent years. In particular reducing the production costs while maintaining high reliability, durability and resistance to harsh working conditions for $\mathrm{Nd}^{3+}$ :YAG lasers pumped with semiconductor diodes.

In most of the previous work on the laser ignition system an optical system was used to focus the laser beam in one or several points in the cylinder volume, which leads to the formation of plasma. The local energy density obtained in this way produced conditions somewhat similar to the conditions present between the electrodes of the spark plug at flashover time. The concept proposed in this article, where the aim of adding carbon nanotubes to fuel is a drastic reduction of the minimum ignition energy, should be stressed as a different solution. This way the relatively small energy laser beam does not have to be focused, but purposeful shaping of the beam could be used as a method to force the ignition in a controlled, much larger selected volume of space in the cylinder. Despite the distinct concepts presented here, the results of previous work on the laser ignition of conventional fuels shown below can be used for the realization of the concepts proposed in the article.

- Ignition of conventional fuel usually uses a laser beam with a pulse energy in the range of one to several tens of $\mathrm{mJ}$. To achieve laser ignition of hydrocarbon fuels an power density (laser pulse intensity) in the range of $1010-1011 \mathrm{~W} / \mathrm{cm}^{2}$ is needed [61].
- Diode pumped $\mathrm{Nd}^{3+}$ :YAG lasers are typically used, with a primary wavelength of $1064 \mathrm{~nm}$, second harmonic of $532 \mathrm{~nm}$, but also $\mathrm{CO}_{2}$ gas lasers emitting infrared later have been used successfully.

- The ignition volume in which a forced laser ignition occurs is greater than that of the spark between the electrodes of the spark plug, it is also true for focused laser beam ignition systems.

- In the case of previously conducted studies of conventional hydrocarbon fuels the non-resonant ignition mechanism plays a dominant role.

- No electrodes common for the spark plug ignition systems facilitates intentional shaping of the fuel dose movement in the cylinder in the compression process and then improves the spread of flame and reduces heat dissipation at the early stage of the flame development.

- It is assumed that four different mechanisms can lead to the laser ignition of fuel: thermal initiation, nonresonant breakdown, resonant breakdown, and photochemical ignition.

- In the case of previously conducted studies of conventional hydrocarbon fuels a dominant role is attributed to the mechanism of non-resonant ignition [61]. For a fuel with a suspension of carbon nanotubes, especially in the presence of iron oxide thermal ignition mechanism plays a crucial role, the authors attribute the potentially the most promising role to the occurrence of the other two effects in the presence of carbon nanotubes.

\section{Conclusions}

The development of the world economy and an increase in the number of cars forces a search for new, more environmentally friendly technical solutions for transport. The article presents the concept of a new piston combustion engine system. The originality of the concept is to combine the latest achievements in the field of nanotechnology in the construction of lasers and the production of biofuels, to use the existing synergies to contribute to improving the combustion engines environmental performance.

The concept presented in the article is the use of ethanol as a fuel where a suspension of carbon nanotubes would be formed, which are characterized by the ability to force ignition using a light pulse. A laser was chosen as the source of the light pulse, while changing the shape of the light beam penetrating the combustion chamber would allow control of the position and the size of the area in which the ignition of fuel would be induced.

The futuristic concept of an engine combustion system has been proposed because it allows achieving a number of synergistic benefits, the most important of them are listed below.

- Ethanol is a fuel with a high ecological potential, thus it is already widely used in the world as an additive to gasoline. The particularly attractive aspects of this fuel are the possible future methods of its production, which could achieve zero carbon dioxide emissions in the fuel production process.

- Properties of ethanol, such as a high octane number and high vaporization heat, make it a very attractive fuel for future engines regardless of the environmental benefits, 
allowing for the further development of the concept of downsizing.

- The preliminary results in the article allow to conclude that among all the most common engine fuels ethanol allows for the creation of the most stable carbon nanotubes dispersions, effectively limiting the phenomena of agglomeration and sedimentation.

- The ability of carbon nanotubes to undergo ignition induced with a pulse of light is their unique feature. Independent studies have shown that nanotubes interacting with ferrocene may force the ignition of conventional hydrocarbon fuel with just the light of camera flash. A higher rate of combustion and wider flammability limits of the mixture (in a wider lambda range) is obtained this way compared with the conventional spark ignition.

- Replacement of the camera flash used by foreign authors with laser light allows taking advantage of the unique characteristics of laser light. Key advantages of the laser is a shorter pulse duration and energy concentration in the beam higher by several orders of magnitude and a unique opportunity to shape the laser beam with simple optics.

At the same time, problems that may hinder the practical application of the described concept have been identified.

- Carbon nanotubes are a relatively recently discovered material and therefore their impact on the environment and human health is not yet fully understood [35, 43, $44,61]$. Although nanotubes do not exhibit acute toxicity, and therefore they are for example intentionally introduced into the human body to accelerate the mending of broken bones [33], or are used to filter the air in the life support systems of spacecraft [18]. It is uncertain, however, whether or not they have any negative longterm health effects resulting from interaction with the human body.

- Many studies point to the carcinogenic effect of pristine cnt nanotubes growth in the cvd process, which have metal nanoparticles incorporated on their surface. Therefore the use of ferrocene in the presented concept combustion system should be restricted.

Further studies are necessary to verify the proposed concept, and in particular a fuel injection technique into the pressure chamber and then testing the engine is required. Regardless of the results of engine research it is necessary to shed light on the impact of nanoparticles emitted by the engine on the environment and human health. This issue is particularly relevant in a broader context, because nanoparticles are added to fuels more and more often - for both petrol and diesel fuel as anti-knock and soot oxidation catalyst additives.

\section{Acknowledgements}

The authors would like to thank all those who contributed to the final outcomes presented in the paper, by giving inspiration for the research, supporting laboratory tests, scientific cooperation, development and revision of the article. We are particularly thankful to David Carnahan, the president of NanoLab Inc., who was the exclusive supplier of CNT's used in our research.

The study presented in this article was performed within the statutory research.

\section{Nomenclature}

FFV flexible fuel vehicle

SWCNT single-walled carbon nanotube

MWCNT multi-wall carbon nanotubes

CVD chemical vapor deposition
DLC diamond like carbon

NP nanoparticles

ODA octadecylamine

\section{Bibliography}

[1] AJAYAN, P.M., TERRONES, M., DE LA GUARDIA, A., HUC, V. et al. Nanotubes in a flash ignition and reconstruction. Science. 2002, 296, 705.

[2] ALDAJAH, S., HAIK, Y., ELNAJJAR, E. A novel dual effect soot filtering system. Jordan Journal of Mechanical and Industrial Engineering. 2010, 4, 75-78.

[3] ALUKER, E.D., KRECHETOV, A.G., MITROFANOV, A.Y., ZVEREV, A.S. et al. Understanding limits of the thermal mechanism of laser initiation of energetic materials. The Journal of Physical Chemistry. 2012, 116, 2448224486.

[4] BADAKHSHAN, A., DANCZYK, S. Ignition of nanoparticles by a compact camera flash. Air Force Research Laboratory Combustion Devices Branch, In-House Interim Report, September 2014.

[5] BADAKHSHAN, A., DANCZYK, S. Photo-ignition of carbon nanotube for ignition of liquid fuel spray and solid fuel. TMS Annual Meeting, 11-14.03.2012, Orlando, USA.
[6] BALAT, M., BALAT, H. Recent trends in global production and utilization of bio-ethanol fuel. Applied Energy. 2009, 86, 2273-2282.

[7] BANAPURMATH, N.R., RADHAKRISHNAN, S., TUMBAL, A.V., NARASIMHALU, T.N. et al. Experimental investigation on direct injection diesel engine fuelled with graphene, silver and multiwalled carbon nanotubes-biodiesel blended fuels. International Journal of Automotive Engineering and Technologies. 2014, 3, 129-138.

[8] BAUGHMAN, R.H., ZAKHIDOV, A.A., DE HEER, W.A. Carbon nanotubes - the route toward applications. Science. 2002, 297, 787-792.

[9] BHUSHAN, B. Springer Handbook of Nanotechnology, third edition, Springer-Verlag, Berlin-Heidelberg 2010.

[10] BRAND, L., GIERLINGS, M., HOFFKNECHT, A., WAGNER, V. et al. Kohlestoff-Nanorörchen: Potenziale einer neuen Materialklasse für Deutschland; Technologieanalyse, VDI Technologiezentrum GmbH, Düsseldorf 2009.

[11] CARLUCCI, A.P., CICCARELlA, G., STRAFELlA, L. Multiwalled carbon nanotubes (MWCNTs) as ignition 
agents for air/methane mixtures. IEEE Transactions on Nanotechnology. 2016, 15, 699-704.

[12] CARLUCCI, A.P., STRAFELLA, L. Air-methane mixture ignition with multi-walled carbon nanotubes (MWCNTs) and comparison with spark ignition. Energy Procedia. 2015, 82, 915-920.

[13] CARLUCCI, A.P., VISCONTI, P., PRIMICERI, P., STRAFELLA, L. et al. Photo-induced ignition of different gaseous fuels using carbon nanotubes mixed with metal nanoparticles as ignitor agents'. Combustion Science and Technology. Accepted for publication, posted online: 08.11.2016.

[14] CHAUVEAU, V. Le pouvoir lubrifiant des nanotubes de carbonne; PhD dissertation. L'Ecole Centrale de Lyon, 2010.

[15] CHEHROUDI, B. Activation and control of autoignition in HCCI engines using volumetrically-distributed ignition of as-produced single-walled carbon nanotubes. SAE Technical Paper. 2012, 2012-01-1691.

[16] CHEHROUDI, B. Minimum ignition energy of the lightactivated ignition of single-walled carbon nanotubes (SWCNTs). Combustion and Flame. 2012, 159, 753-756.

[17] CHEHROUDI, B. Nanotechnology and applied combustion: use of nanostructured materials for light-activated distributed ignition of fuels with propulsion applications. Recent $\mathrm{Pa}$ tents on Space Technology. 2011, 1, 107-122.

[18] CINKE, M., LI, J., CHEN, B., WIGNARAJAH, K. et al. Development of Metal-impregnated Single Walled Carbon Nanotubes for Toxic Gas Contaminant Control in Advanced Life Support Systems. SAE Technical Paper. 2003, $2003-$ 01-2368.

[20] Coordinating Research Council, Fuel Permeation from Automotive Systems: E0, E6, E10, E20 and E85. Final Report, 2006.

[20] DE VOLDER, M.F.L., TAWFICK, S.H., BAUGHMAN, R.H., HART, A.J. Carbon nanotubes: present and future commercial applications. Science. 2013, 339, 535-539.

[21] DIKIO, E.D. Morphological characterization of soot from the atmospheric combustion of diesel fuel. International Journal of Electrochemical Science. 2011, 6, 2214-2222.

[22] DODD, R., MULLETT, J., CARROLL, S., DEARDEN, G. et al. Laser ignition of an IC test engine using an Nd: YAG laser and the effect of key laser parameters on engine combustion performance. Lasers in Engineering. 2007, 17(3), 1554-2971.

[23] FINIGAN, D.J., DOHM, B.D., MOCKELMAN, J.A., OEHLSCHLAEGER, M.A. Deflagration-to-detonation transition via the distributed photo ignition of carbon nanotubes suspended in fuel/oxidizer mixtures. Combustion and Flame. 2012, 159, 1314-1320.

[24] FRIDELL, E., HAEGER-EUGENSSON, M., MOLDANOVA, J., FORSBERG, B. et al. A modelling study of the impact on air quality and health due to the emissions from E85 and petrol fuelled cars in Sweden. Atmospheric Environment. 2014, 82, 1-8.

[25] FU, S., YU, L., HU, Y., WANG, C. et al. Impact of carbon nanotube suspensions on the hotplate ignition of liquid fuels. 2010 International Conference on Mechanic Automation \& Control Engineering (MACE), 26-28.06.2010, Wuhan, China.

[26] GAN, Y., QIAO, L. Optical properties and radiationenhanced evaporation of nanofluid fuels containing carbonbased nanostructures. Energy Fuels. 2012, 26, 4224-4230.

[27] HAREL, S., KHAIRNAR, M., SONAWANE, V. Laser ignition system for IC engines. International Journal of Science and Research. 2014, 3, 1551-1560.
[28] HUANG, Y.Y., TERENTJEV, E.M. Dispersion of carbon nanotubes: mixing, sonication, stabilization and composite properties. Polymers. 2012, 4, 275-295.

[29] HUANG, Z., KAN, W., LU, Y., CHENG, T. et al. Effect of nanoparticle suspensions on liquid fuel hot-plate ignition. Journal of Nanotechnology in Engineering and Medicine. 2014, 5, 31004-31004-5.

[30] KAŁUŻNY, J. Experimental applications of carbon nanotubes in the construction of internal combustion engines. Publishing House of Poznan University of Technology, Poznań 2013.

[31] KAŁUŻNY, J., CZAJKA, J., PIELECHA, I., WISŁOCKI, $\mathrm{K}$. Investigations of the fuel injection and atomization with the use of laser illumination. Combustion Engines. 2013, 154, 469-475.

[32] KAŁUŻNY, J., MERKISZ-GURANOWSKA, A., GIERSIG, M., KEMPA, K. Lubricating performance of carbon nanotubes in internal combustion engines - engine test results for cnt enriched oil. Internal Report.

[33] KAR, K.K., PANDEY, J.K., RANA, S.K. (Eds.) Handbook of Polymer Nanocomposites. Processing, Performance and Application Volume B: Carbon Nanotube Based Polymer Composites. Springer-Verlag Berlin Heidelberg, 2015.

[34] KISH, S.S., RASHIDI, A., AGHABOZORG, H.R., MORADI, L. Increasing the octane number of gasoline using functionalized carbon nanotubes. Applied Surface Science. 2010, 256, 3472-3477.

[35] KOLOSNJAJ-TAB, J., JUST, J., HARTMAN, K.B., LAOUDI, Y. et al. Anthropogenic carbon nanotubes found in the airways of Parisian children. EBioMedicine. 2015, 2, 16971704.

[36] LAGALLY, C.D., REYNOLDS, C.C.O., GRIESHOP, A.P., KANDLIKAR, $M$. et al. Carbon nanotube and fullerene emissions from spark-ignited engines. Aerosol Science and Technology. 2012, 46, 156-164.

[37] MANOJ, B., SREELAKSMI, S., MOHAN, A.N., KUNJOMANA, A.G. Characterization of diesel soot from the combustion in engine by $\mathrm{x}$-ray and spectroscopic techniques. International Journal of Electrochemical Science. 2012, 7, 3215-3221.

[38] MERKISZ, J., PIELECHA, J. Selected experiences in RDE in Polish reality for different combustion engine applications. 4rd International Conference "Real Driving Emissions", Berlin 25-27.10.2016.

[39] MERKISZ, J., PIELECHA, J. Selected remarks about RDE test. Combustion Engines. 2016, 166(3), 54-61.

[40] MERKISZ, J., PIELECHA, J., BIELACZYC, P., WOODBURN, J. Analysis of emission factors in RDE tests as well as in NEDC and WLTC chassis dynamometer tests. SAE Technical Paper. 2016, 2016-01-0980.

[41] MIRZAJANZADEH M., TABATABAEI M., ARDJMAND M., RASHIDI A. et al. A novel soluble nano-catalysts in diesel-biodiesel fuel blends to improve diesel engines performance and reduce exhaust emissions. Fuel. 2015, 139, 374-382.

[42] MORSY, M.H. Review and recent developments of laser ignition for internal combustion engines applications. Renewable and Sustainable Energy Reviews. 2012, 16(7), 4849-4875.

[43] MURR, L.E., BANG, J.J., ESQUIVEL, E.V., GUERRERO, P.A. et al. Carbon nanotubes, nanocrystal forms, and complex nanoparticle aggregates in common fuel-gas combustion sources and the ambient air. Journal of Nanoparticle Research. 2004, 6, 241-251.

[44] MURR, L.E., GUERRERO, P.A. Carbon nanotubes in wood soot. Atmospheric Science Letters. 2006, 7, 93-95. 
[45] OHKURA, Y., RAO, P.M., ZHENG, X. Flash ignition of Al nanoparticles: Mechanism and applications. Combustion and Flame. 2011, 158, 2544-2548.

[46] PHUOC, T.X. Laser-induced spark ignition fundamental and applications. Optics and Lasers in Engineering. 2006, 44, 351-397.

[47] RAMACHANDRAN, S., STIMMING, U. Well to wheel analysis of low carbon alternatives for road traffic. Energy \& Environmental Science. 2015, 8, 3313-3324.

[48] RASHEDUL, H.K., MASJUKI, H.H., KALAM, M.A., ASHRAFUL, A.M. et al. The effect of additives on properties, performance and emission of biodiesel fuelled compression ignition engine. Energy Conversion and Management. 2014, 88, 348-364.

[49] SARVESTANI, N.S., ROHANI, A., FARZAD, A., AGHKHANI, M.H. Modeling of specific fuel consumption and emission parameters of compression ignition engine using nanofluid combustion experimental data. Fuel Processing Technology. 2016, 154, 37-43.

[50] SCHWADERLAPP, M., ADOMEIT, P., KOLBECK, A., THEWES, M. Ethanol und sein Potenzial für DownsizingMotorenkonzepte. MTZ. 2012, 2.

[51] SELVAN, V. ANAND, R.B., UDAYAKUMAR, M. Effect of cerium oxide nanoparticles and carbon nanotubes as fuelborne additives in diesterol blends on the performance, combustion and emission characteristics of a variable compression ratio engine. Fuel. 2014, 130, 160-167.

[52] SINGAMANENI, S., SHEVCHENKO, V., BLIZNYUK, V. Unusual ignition behavior of polyurethane/carbon nanotube composites with a $\mathrm{He}-\mathrm{Ne}$ laser excitation $(632.8 \mathrm{~nm})$ during micro-Raman spectroscopy. Carbon. 2006, 44, 2191-2195.

[53] SUAREZ-BERTOA, R., ZARDINI, A., KEUKEN, H., ASTORGA C. Impact of ethanol containing gasoline blends on emissions from a flex-fuel vehicle tested over the Worldwide Harmonized Light Duty Test Cycle (WLTC). Fuel. 2015, 143, 173-182.

[54] SUNDSETH, K., LOPEZ-APARICIO, S., SUNDVOR, I. Bioethanol vehicle transport in Oslo as climate policy: what are the social economic costs resulting from acetaldehyde pollution effects? Journal of Cleaner Production. 2015, 108, 1157-1167.

[55] SWANSON, J., FEBO, R., BOIES, A., KITTELSON, D. Fuel sulfur and iron additives contribute to the formation of

\author{
Jarosław Kałużny, DSc., DEng. - Faculty of Ma- \\ chines and Transport at Poznan University of Tech- \\ nology. \\ e-mail: Jaroslaw.Kaluzny@put.poznan.pl
}

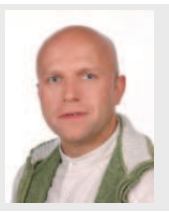

Dawid Gallas, MSc. - Faculty of Machines and Transport at Poznan University of Technology.

e-mail: Dawid.Gallas@doctorate.put.poznan.pl

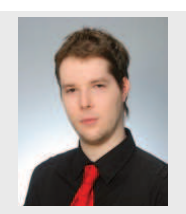

Miłosław Kozak, DSc., DEng. - Faculty of Machines and Transport at Poznan University of Technology.

e-mail: Miloslaw.Kozak@put.poznan.pl carbon nanotube-like structures in an internal combustion engine. Environmental Science \& Technology Letters. 2016, 10, 364-368.

[56] SYSOEV, N.N., OSIPOV, A.I., UVAROV, A.V., KOSICHKIN, O.A. Flash ignition of a carbon nanotube. Moscow University Physics Bulletin. 2011, 10, 66(5).

[57] TREWARTHA, S. Light ignition of carbon nanotubes for the initiation of energetic materials. PhD Thesis. 2015, Flinders University, School of Chemical and Physical Sciences.

[58] TSENG, S.H., TAI, N.H., HSU, W.K., CHEN, L.J. et al. Ignition of carbon nanotubes using a photoflash. Carbon. 2007, 45, 958-964.

[59] VDI Richtlinie, VDI 2840, Kohlenstoffschichten Grundlagen, Schichttypen und Eigenschaften.

[60] Volkswagen SSP 359; 1.41 TSI Engine with dual-charging.

[61] WANG, J., ONASCH, T.B., GE, X., COLLIER, S. et al. Observation of fullerene soot in eastern China. Environmental Science \& Technology Letters. 2016, 3, 121-126.

[62] WILLAND, J., DANIEL, M., MONTEFRANCESCO, E., GERINGER, B., et al. Grenzen des Downsizing bei Ottomotoren durch Vorentflammungen. MTZ. 2009, 5.

[63] WILLAND, J., SCHINTZEL, K., HOFFMEYER, H. Das Potential aufgeladener Ottomotoren mit Direkteinspritzung. MTZ. 2009, 2.

[64] Worldwide Fuel Charter, 2013.

[65] www.afdc.energy.gov/afdc/data/

[66] www.continuumlasers.com

[67] www.nano-lab.com

[68] www.nano-lab.com/nanotubesuspensions.html

[69] XIE, H., LEE, H., YOUN, W., CHOI, M. Nanofluid containing multiwalled carbon nanotubes and their enhanced thermal conductivities. Journal of Applied Physics. 2003, 94, 4967-4971.

[70] ZACCARDI, J-M., LECOMPTE, M., DUVAL, L., PAGOT, A. Vorentflammung an hoch aufgeladenen Ottomotoren; Visualisierung und Analyse. MTZ. 2009, 12.

[71] ZHAO, H. Laser diagnostics and optical measurement techniques in internal combustion engines. SAE International, 2012, Warrendale, USA.

[72] ZHAO, H., LADOMMATOS, N. Optical diagnostics for incylinder mixture formation measurements in IC-engines. Progress in Energy and Combustion Science. 1998, 24, 297 336.

Prof. Jerzy Merkisz, DSc., DEng. - Faculty of Machines and Transport at Poznan University of Technology.

e-mail: Jerzy.Merkisz@put.poznan.pl

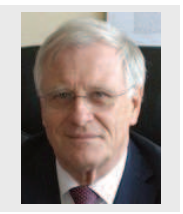

Tomasz Runka, DSc. - Faculty of Technical Physics at Poznan University of Technology.

e-mail: Tomasz.Runka@put.poznan.pl
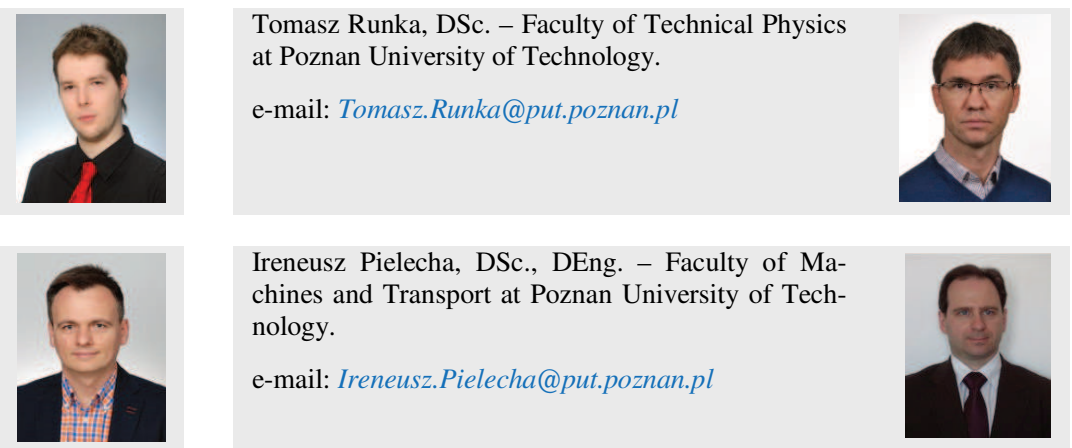

Ireneusz Pielecha, DSc., DEng. - Faculty of Machines and Transport at Poznan University of Technology.

e-mail: Ireneusz.Pielecha@put.poznan.pl

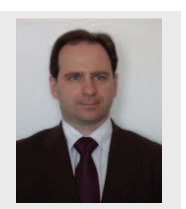

